\title{
ANÁLISE DA HOMOGENIZAÇÃO DO NIÓBIO NA LIGA DE ALUMÍNIO 5052F PELO FORJAMENTO PROVOCADO PELO PROCESSO FRICTION STIR WELDING*
}

\author{
Gabriel Pessoa Vilas Boas ${ }^{1}$ \\ Paulo D'angelo Costa Assunção ${ }^{2}$ \\ Ivone Thatianne de Abreu dos Passos Cardoso ${ }^{1}$ \\ Paulo Sérgio da Silva Portal ${ }^{1}$ \\ Elenildo Barros da Silva ${ }^{3}$
}

\section{Resumo}

O presente artigo apresenta um estudo sobre a mistura do nióbio em chapas de alumínio pelo processo Friction Stir Welding (FSW), levando em consideração o efeito de forjamento envolvido na soldagem. O processo FSW, consiste em utilizar uma ferramenta rotativa que em contato com o material a ser soldado gera atrito, provocando aumento de temperatura e deformação plástica. O aquecimento gerado é abaixo do ponto de fusão dos materiais envolvidos, por isso é considerado como solda em estado sólido. Para alcançar os objetivos desta pesquisa, conta-se com a colaboração da Companhia Brasileira de Metalurgia e Mineração (CBMM), que forneceu amostras de Nióbio Metálico em cavaco para proceder aos experimentos deste artigo. A amostra adquirida foi triturada manualmente, em seguida, cominuido em moinho de bola para obtê-lo em forma de pó, viabilizando, assim, a inserção na junta a ser soldada. O nióbio foi colocado entre dois metais de base de Al-Mg 5052F que foi soldado pelo processo FSW, em uma máquina adaptada para esse processo. Após a soldagem foi feito a metalografia na seção transversal onde observou-se uma boa mistura do nióbio no metal soldado. Além disso, foi analisado a microestrutura formada e a composição química através do microscópio eletrônico de varredura (MEV).

Palavras-chave: Soldagem; Friction Stir Welding; Nióbio; Microscopia Eletrônica de Varredura.

\section{HOMOGENIZATION ANALYSIS FROM NIOBIUM IN THE ALUMINIUM ALLOY THROUGH Abstract THE FORGING CAUSED FOR THE FRICTION STIR WELDING PROCESS}

This article presents study about the features of the Niobium and its introduction on the Aluminum sheets by the Friction Stir Welding (FSW), taking account the forging effect involved in welding. The FSW process, where we can call of friction welding with a nonconsumable pin, it consists on utilizes a rotary tool which in contact with the stuff to be welded creates friction, causing heat and plastic deformation. This heat is below from the melting point of the stuff involved, so it's considered as solid state welding. For achieve the goals of this research, it's necessary the collaboration of the "Companhia Brasileira de Metalurgia e Mineração" (CBMM), that provides samples of Metal Niobium chips which proceeded the experiments of this article. The acquired sample was crushed by hand, then, it was comminuted in a ball mill to obtain it in powder form, in this way enabling the insertion on the point to be welded. The Niobium was put between two base metals, then it was welded by the FSW process. After welding, it was done the metallography in the transversal section, where was observed a satisfactory mixture in the metal welded. Besides that, it was verified microstructure formed and chemical composition by scanning electron microscopy (SEM).

Keywords: Welding; Friction Stir welding; Niobium; Scanning electron microscopy (SEM).

1 Graduação em Engenharia Mecânica, discente, Faculdade Estácio de Belém, Campus IESAM, Belém, Pará, Brasil.

2 Doutorando em engenharia de recursos naturais, Mestre em engenharia mecânica, docente, Universidade Federal do Pará, Belém, Pará, Brasil.

3 Graduação em Engenharia Mecânica, Especialista em Engenharia de produção, docente, Faculdade Estácio de Belém, Campus IESAM, Belém, Pará, Brasil 


\section{INTRODUÇÃO}

O processo de soldagem, Friction Stir Welding (FSW), proposto neste trabalho, se refere a uma técnica em que uma ferramenta de elevada resistência mecânica e com um perfil especial é utilizada para, mediante atrito com as peças a serem soldadas, gerar aumento de temperatura promovendo a mistura mecânica dos materiais envolvidos, assim consolidando a solda, Thomas [1]. O alumínio por ser considerado um metal com baixo peso específico, aliado a alta resistência mecânica, faz com que seja a primeira escolha em termos de material para atender as exigências de determinadas aplicações nas indústrias.

Além disso, outra questão que merece destaque é a da reciclagem deste metal, cerca de $90 \%$ do alumínio presente em veículos é recuperado e reciclado, com enormes vantagens ambientais e econômicas [2]. Entretanto, temos como desvantagem deste metal, a dificuldade no processo de soldagem, uma vez que propriedades das ligas deste metal acabam se degradando e problemas de solidificação, como tensões residuais e trincas, podem ocorrer na fusão do metal quando o alumínio é submetido a soldagem por processos convencionais.

Alternativas visando contornar esta dificuldade, imposta por processos tradicionalmente utilizados, como Metal Inert Gas (MIG) ou Tungsten Inert Gas (TIG), surge a utilização de soldagem por fricção acima citada, onde a união das peças ocorre sem fusão do material base.

O processo de soldagem por FSW apresenta diversas vantagens quando comparado aos processos onde ocorre a fusão do metal, principalmente no que diz respeito a sua aplicabilidade no alumínio e suas ligas, que por ocorrer na fase solida, pode eliminar boa parte dos problemas que vem a ocorrer na solidificação, amenizando as distorções de chapas finas, o aparecimento de trincas, a conservação de boa parte das propriedades mecânicas, melhorando a ductilidade, a fadiga e a tenacidade à fratura, o que resulta em suportar elevadíssimas pressões. Além disso, não é necessário metal de adição, portanto, não há produção de gases nocivos à saúde e nem ao meio ambiente, sendo um processo eficiente em energia de acordo com Cruz [3].

Como desvantagens do processo FSW, tem-se a necessidade de um sistema rígido para realizar o processo de fixação, a necessidade da presença de um furo no final da solda para realização do processo e há uma relativa dificuldade de soldar materiais com alto ponto de fusão, essa por sua vez pode ser justificada porque o aumento da temperatura é gerado pelo atrito da ferramenta com a peça no momento da soldagem.

Cabe ressaltar, que a geometria da ferramenta e os parâmetros de soldagem são fatores imprescindíveis para o processo de soldagem por atrito. Alguns fatores influenciam no escoamento do material e na qualidade da solda no processo FSW, quais sejam, tipo de junta, velocidade de rotação da ferramenta, velocidade de soldagem, inclinação da ferramenta, profundidade e penetração do pino, conforme disposto por Capelari em sua pesquisa científica, publicada em 2006 [4]. Apesar do processo FSW conservar a maioria das propriedades mecânicas do alumínio, por se tratar de soldagem por atrito, ocorrem na zona de mistura, consideráveis perdas de resistência mecânica e por esse motivo ainda é limitado o uso deste processo nas indústrias.

Nesse sentido, buscando aprimorar a soldagem por atrito, surgem os processos que utilizam particulado metálico ou compósitos não estruturados. Esse processo é derivado do (FSW) que vem a ser chamado de Friction Powder Processing (FPP). $\mathrm{O}$ 
resultado na aplicação em ligas de alumínio - cobre onde foi colocado pó de alumínio - cobre no Gap entre as juntas soldadas, foi observado a melhoria significativa nas propriedades mecânicas das juntas soldadas e o desaparecimento de vazios no metal de solda como abordado por Inada [5].

Pelo exposto, a relevância deste trabalho consiste no estudo de uma solda realizada pelo processo de FSW em chapas de alumínio-magnésio 5052F, com adição de nióbio, fazendo a investigação do efeito dessa adição nas juntas soldadas, como avaliação metalografica, análise da secção transversal do cordão de solda, verificação da microestrutura do material soldado por Microscopia Eletrônica de Varredura (MEV). Além disso, será realizado uma análise dos efeitos do forjamento na soldagem por FSW, por se tratar de um processo de fabricação que dá forma aos metais por meio da força de compressão, estando diretamente relacionado ao processo FSW que causa pressão e um aumento de temperatura através de uma ferramenta rotativa na junta a ser soldada.

Em relação as referências acerca dos possíveis resultados e efeitos da mistura de nióbio com alumínio, na tese de mestrado de Mariano em 2008 [6], foi abordada a compressibilidade de misturas de pós de alumínio e nióbio, por moagem de bolas de alta energia, sendo utilizado ácido esteárico como agente controlador do processo, neste caso verificou-se a possibilidade de agregação do alumínio com nióbio na fase sólida, mas nenhuma referência relacionada aos efeitos na mistura de alumínio e nióbio no processo de soldagem por FSW motivando a pesquisa deste trabalho.

A amostra de Nióbio Metálico estudada neste trabalho foi fornecida pela Companhia Brasileira de Metalurgia e Mineração (CBMM), principal empresa de exploração de nióbio no Brasil. A escolha desse metal como elemento de liga foi em virtude de sua resistência a alta temperatura e a corrosão e boas propriedades mecânicas.

\section{MATERIAIS E MÉTODOS}

\subsection{Cominuição e peneiramento do nióbio}

Para viabilizar a adição do nióbio na junta a ser soldada, as amostras de cavaco de nióbio foram trituradas, em seguida, cominuídas em um moinho de bola (Figura 1) a uma velocidade de aproximadamente $41,88 \mathrm{rad} / \mathrm{s}$, por 4 horas, repetindo 0 processo 4 (quatro) vezes. Logo após, o material foi colocado em uma peneira (Figura 2) com abertura de 35 Mesh para selecionar suas menores partículas que foram adicionadas na junta a ser soldada.

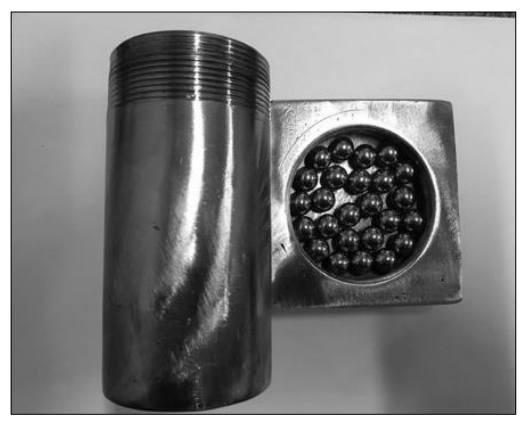

Figura 1. Moinho de bola.

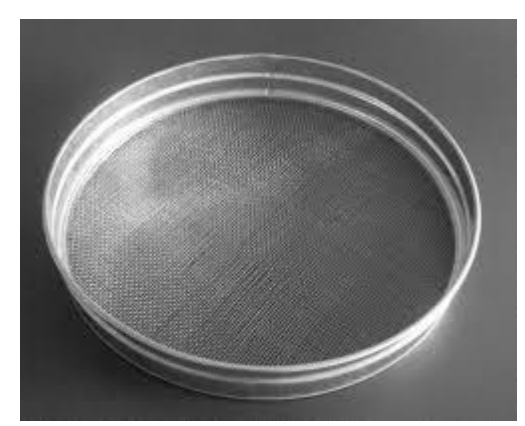

Figura 2. Peneira. 


\subsection{Processo de soldagem FSW}

Após a redução do Nióbio em pó, foram fixadas duas peças de Al-Mg 5052F como metais de base, de maneira firme para que não ocorresse o afastamento entre elas na máquina adaptada para soldagem por FSW (Figura 3). A Tabela 1 representa a composição química das peças de alumínio $5052 \mathrm{~F}$ utilizadas na soldagem.

Tabela 1. Composição química do alumínio Al-Mg 5052F. ASM, 2013.

\begin{tabular}{|c|c|c|c|c|c|c|c|}
\hline \multicolumn{7}{|c|}{ Composição química } \\
\hline $\mathrm{Mg}(\%)$ & $\mathrm{Fe}(\%)$ & $\mathrm{Cu}(\%)$ & $\mathrm{Mn}(\%)$ & $\mathrm{Cr}(\%)$ & $\mathrm{Zn}(\%)$ & $\mathrm{Al}$ & Outros \\
\hline $\begin{array}{c}2,20- \\
2,80\end{array}$ & 0,40 & 0,10 & 0,10 & $\begin{array}{c}0,15- \\
0,35\end{array}$ & 0,10 & Restante & $0,05-0,15$ \\
\hline
\end{tabular}

A ferramenta utilizada para soldagem foi com probe cilíndrica lisa e shoulder perfilado concêntrico não consumível, com rotação de aproximadamente 178,02 $\mathrm{rad} / \mathrm{s}$ e carga de compressão em torno de $200 \mathrm{~kg}$. Com as peças a serem soldadas fixadas a ferramenta cilíndrica em rotação, foi inserida na junta até o contato do ombro da ferramenta com a superfície superior da junta, gerando aumento de temperatura por meio de atrito. O aquecimento resultante do atrito elevou a temperatura no local para uma média de $200{ }^{\circ} \mathrm{C}$, levando o alumínio ao estado plástico, possibilitando assim, que a ferramenta misturasse os materiais e os unissem. Desta forma, com a deformação plástica do alumínio, iniciou-se o movimento linear manualmente ao longo do eixo de soldagem.

É importante ressaltar, que o escoamento dos materiais em torno do eixo de soldagem promove a mistura no estado sólido dos materiais, originando a solda após o esfriamento do local como comentado por Mishra [7].

O nióbio em pó utilizado como elemento de liga neste processo de soldagem, foi colocado em uma fresta de $1 \mathrm{~mm}$ entre os metais de base (Figura 4). A soldagem foi executada a uma velocidade $1,2 \mathrm{~mm} / \mathrm{s}$, e foi aplicado o deslocamento da ferramenta com tecimento para favorecer a mistura do nióbio com o alumínio. Ato contínuo, foi realizada soldagem com os mesmos parâmetros sem a adição de nióbio para efeito comparativo entre as juntas.

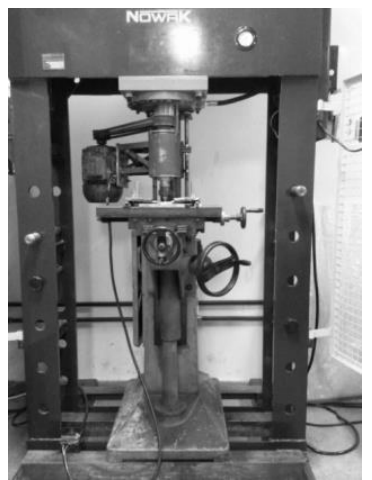

Figura 3. Máquina adaptada para FSW.

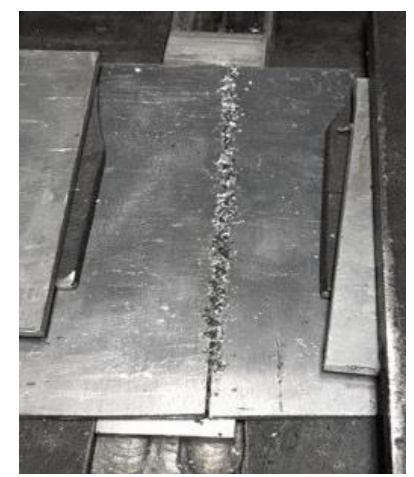

Figura 4. Adição de nióbio na peça. 


\subsection{Metalografia}

Após a soldagem as peças foram cortadas em sua seção transversal na máquina cutoff, conforme as dimensões no desenho técnico (Figura 5). Seguidamente realizado o embutimento à quente da peça soldada em baquelite facilitando, desse modo, os processos de lixamento e polimento do material. O lixamento foi feito na politriz lixadeira que consiste basicamente em lapidar o corpo de prova com lixas de granulometrias cada vez menores.

As lixas usadas dispunham de granulometria 100, 320, 400, 600, 800, 1000, 1200. Durante o processo a direção das amostras eram modificadas a cada $90^{\circ}$, sendo trocada a lixa até que fosse perceptível que não havia nenhum risco contrário ao da direção de lixamento atual. Esse processo teve como finalidade eliminar quaisquer imperfeições ou risco na superfície do material, fornecendo um bom acabamento ao polimento.

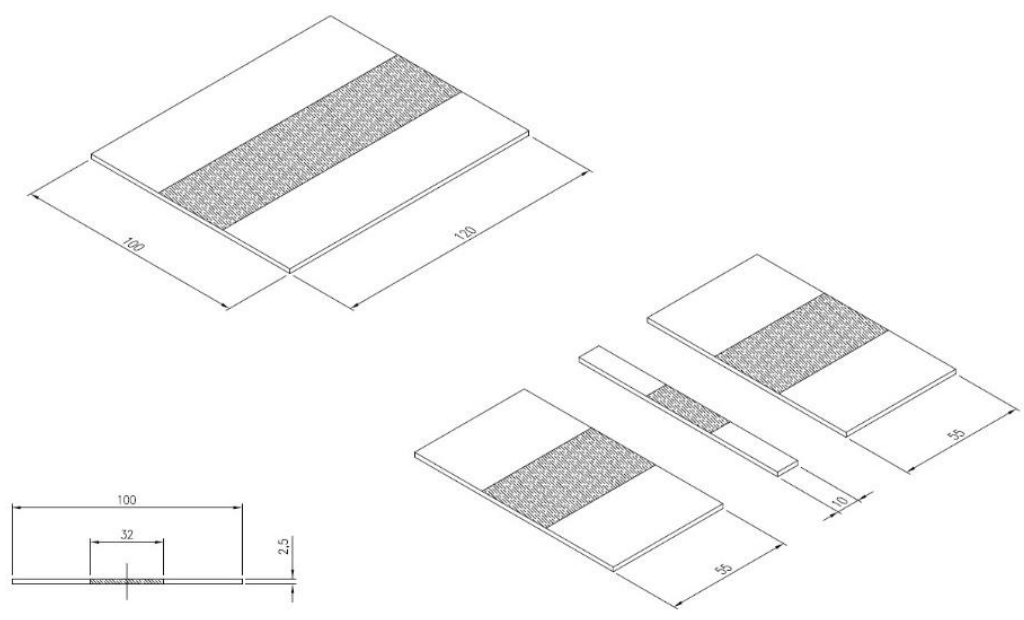

Figura 5. Corte realizado na chapa soldada.

As peças embutidas foram atacadas quimicamente com MARBLE, um reativo metalográfico cuja composição é: 1- $50 \mathrm{ml}$ de ácido clorídrico $(\mathrm{HCl}) ; 2-50 \mathrm{ml}$ de água $(\mathrm{H} 2 \mathrm{O})$; e 3- $4 \mathrm{~g}$ de sulfeto de cobre (CuSO4). Esse tratamento serviu para se obter a revelação da microestrutura do material para realização da macrografia, da micrografia e da microdureza.

Em seguida, as peças atacadas quimicamente foram analisadas no microscópio ZEISS modelo: Axio Lab. A1, onde foi verificado o metal de base, o metal de solda, a zona termicamente afetada e a zona termo mecanicamente afetada. Essa análise foi fundamental para verificação da mistura e do comportamento granular do material soldado, além da possibilidade de verificar e caracterizar possíveis descontinuidades no material soldado.

Como última etapa da metalografia as amostras da peça soldada foram analisadas no microscópio eletrônico de varredura, modelo VEGA 3, com a finalidade de verificar a microestrutura formada na mistura dos materiais, além de verificar a composição química da solda no modo EDS (Energy Dispersive X-Ray). 


\section{RESULTADOS E DISCUSSÃO.}

\subsection{Soldagem FSW}

As Figuras 6 e 7 são os demonstrativos das peças soldadas com e sem nióbio respectivamente. Nas referidas figuras pode-se observar que não há presença de descontinuidade superficial no cordão de solda e de que não apresenta partícula de nióbio superficial. Além disso, não há mudança na coloração do cordão de solda, o que pode ser um indicativo de boa solubilização do nióbio com o alumínio. Durante a soldagem não foi observado anomalias na máquina, nem na ferramenta e nem no metal de base indicando que material adicional não interferiu no processo.

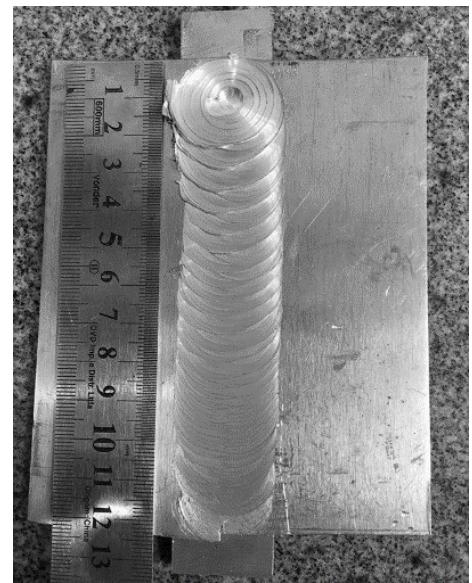

Figura 6. Peça soldada com Nióbio.

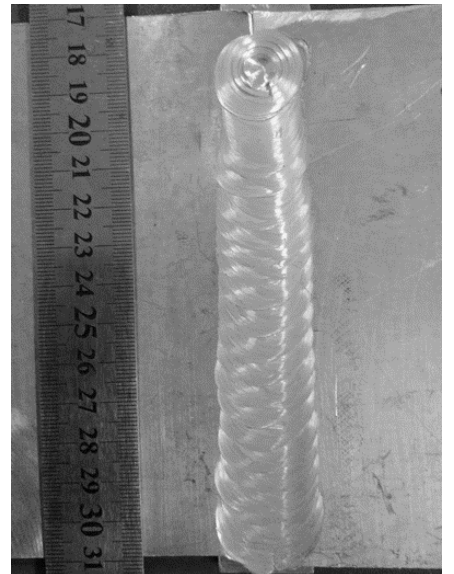

Figura 7. Peça soldada sem Nióbio

\subsection{Avaliação Macroestrutural}

$\mathrm{Na}$ macrografia (Figuras 8 e 9) das seções transversais das peças soldadas foram reveladas as diferentes regiões da solda, sem e com adição de nióbio, respectivamente, onde observou-se algumas descontinuidades na solda sem nióbio. No que tange as peças com nióbio pode-se observar uma boa homogeneidade da solda, sem a presença de descontinuidades, o que pode ser o indicativo de uma melhoria na qualidade da solda.



Figura 8. Macrografia da peça soldada sem nióbio.

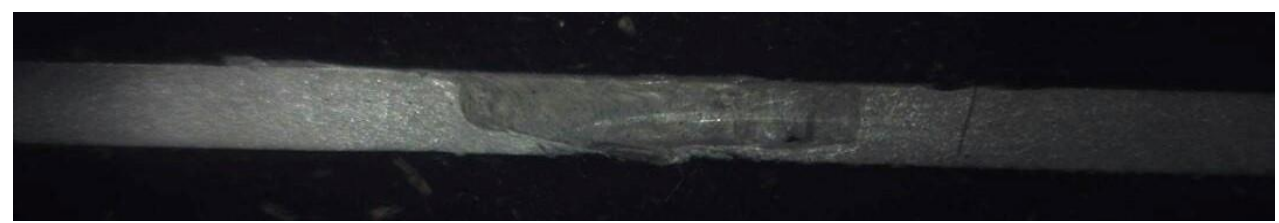

Figura 9. Macrografia da peça com adição de nióbio. 


\subsection{Avaliação da Microestrutura}

A solda realizada sem nióbio apresentou boa mistura no metal de solda que pode ser atribuído ao tecimento aplicado para realizar a soldagem. Na Figura 10 é observado o perfil geométrico do cordão de solda na forma reta replicando o formato da ferramenta utilizada com uma largura maior provocada pelo tecimento e uma descontinuidade nas extremidades inferiores do metal soldado. Essas descontinuidades podem estar relacionadas a operacionalidade de baixa energia de soldagem utilizada e velocidade de deslocamento, bem como angulação da ferramenta. A micrografia revela com mais precisão a ZTA, cuja referência é 100 micrômetros, com isso a ZTA apresentou uma forma muito pequena com alguns tamanhos de grãos relativamente maiores.

$\mathrm{Na}$ zona de mistura foi observado uma estrutura granular muito parecida com uma estrutura forjada, isso pode ser justificado pelo processo do atrito e compressão da ferramenta no material.

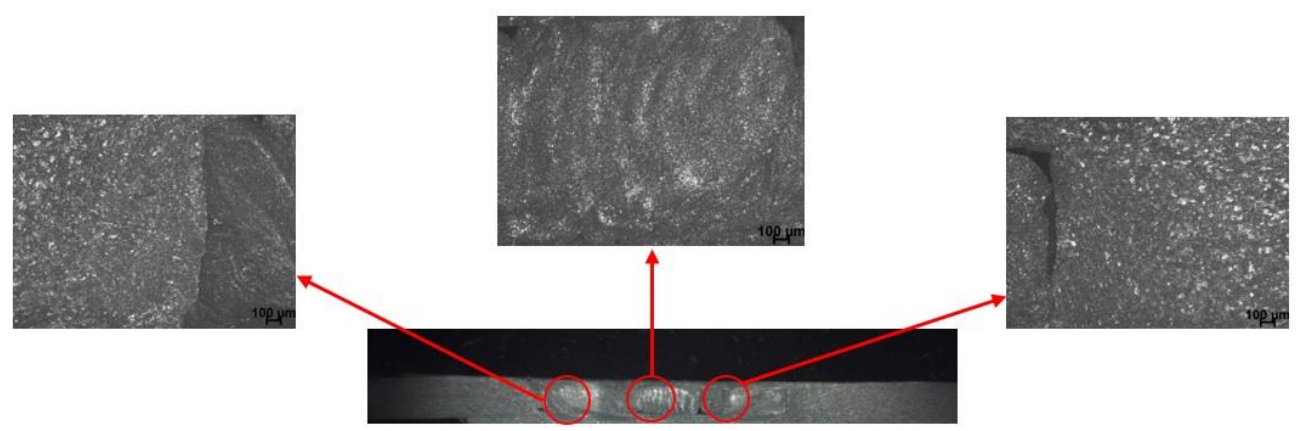

Figura 10. Metal de solda sem nióbio.

A solda realizada com adição de nióbio (Figura 11) mostra o perfil geométrico do cordão de solda muito semelhante a solda sem nióbio, mas com algumas diferenças entre elas, como a ausência de descontinuidade, o que já havia sido observado em um processo semelhante por Inada [5], quando adicionou pó de alumínio - cobre em sua solda.

O aparecimento de zonas de nugget, que corresponde a uma área de recristalização constituída de grãos equiaxiais, podem aumentar a resistência do metal, entretanto o aparecimento do nugget não está relacionado com a termodinâmica do processo como previsto na literatura, uma vez que a solda sem nióbio foi executada com os mesmos parâmetros.

Essa mudança deve estar relacionada com alguma questão metalúrgica, apesar da dificuldade de solubilidade do nióbio no alumínio. A solda apresenta uma estrutura bastante homogênea sem partículas inteiras de nióbio o que indica que os parâmetros de soldagem empregado foram suficientes para transformar o alumínio com o nióbio em uma liga. 


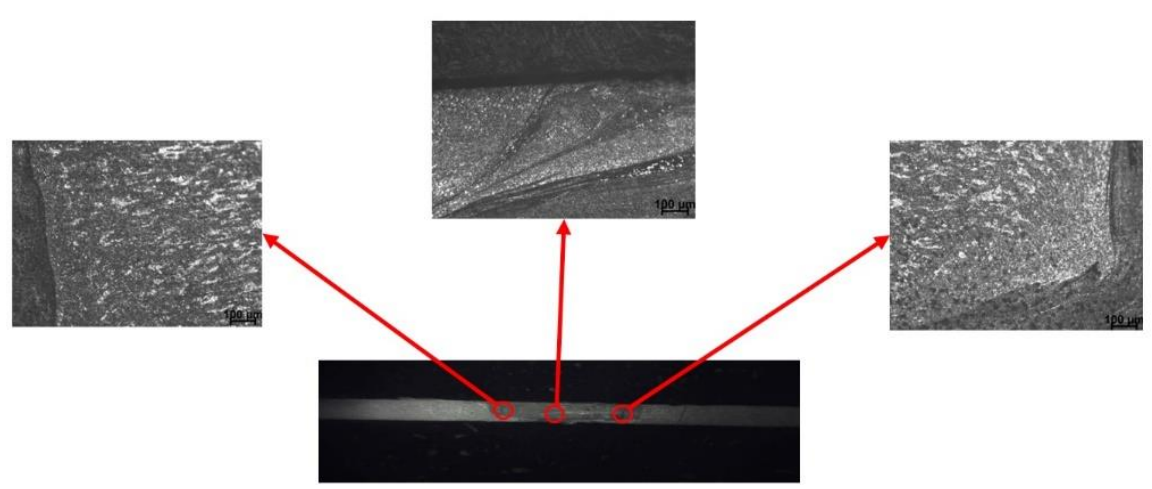

Figura 11. Metal de solda com nióbio.

\subsection{Microscopia Eletrônica de Varredura}

A Figura 12 abaixo representa a análise química realizada em quatro pontos diferentes da amostra e todos os resultados obtidos estão descritos na Tabela 2.
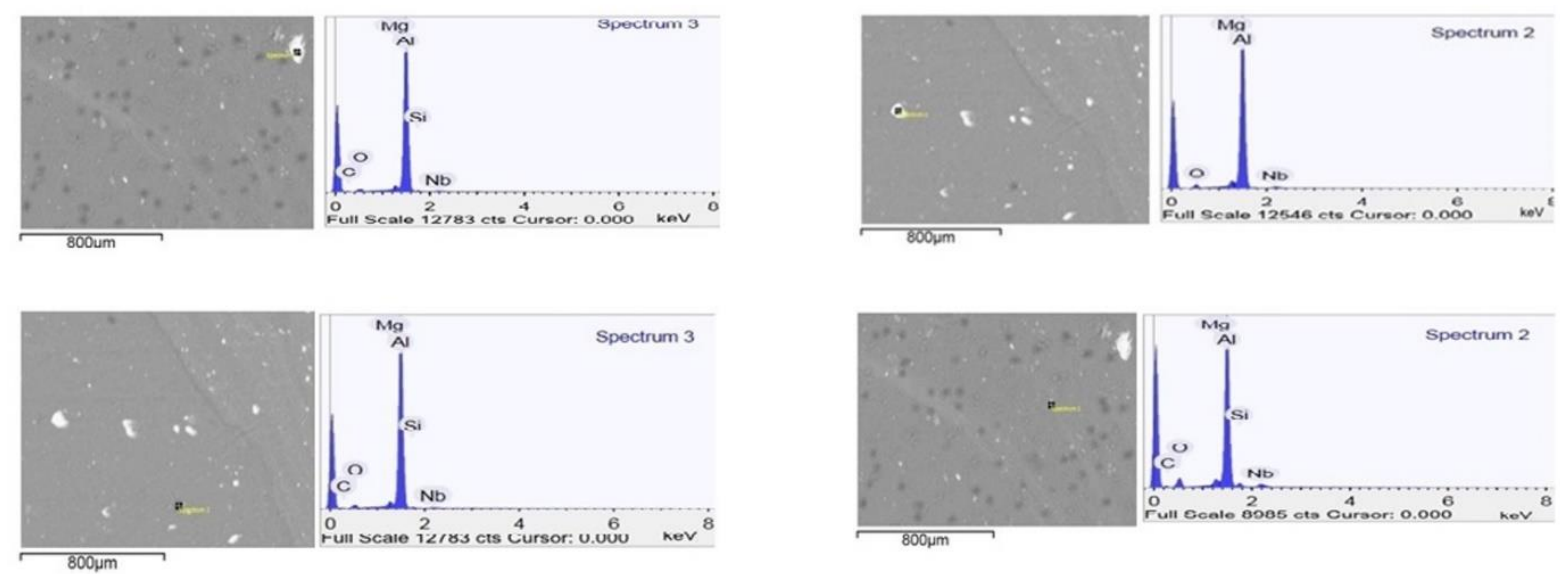

Figura 12. Pontos 1, 2, 3 e 4 da análise química.

Tabela 2. Resultados obtidos através do MEV com recurso EDS.

\begin{tabular}{|c|c|c|c|c|}
\hline \multirow{2}{*}{ Elemento } & \multicolumn{4}{|c|}{ Peso \% } \\
\cline { 2 - 5 } & Ponto 1 & Ponto 2 & Ponto 3 & Ponto 4 \\
\hline Alumínio & 25,16 & 80,39 & 80,12 & 63,07 \\
\hline Magnésio & 1,40 & 2,36 & 2,50 & 2,30 \\
\hline Nióbio & 43,83 & 2,86 & 1,36 & 4,47 \\
\hline Silício & 1,80 & - & 1,15 & 3,40 \\
\hline
\end{tabular}

Com base nos resultados obtidos, as imagens apresentam regiões claras, intermediárias e escuras, entretanto, não podemos afirmar que as regiões claras são partículas de nióbio puro, apesar de no ponto 1 termos uma concentração de $43,83 \%$ de nióbio e $25,16 \%$ de alumínio, temos o inverso no ponto 2 também de cor clara com $2,86 \%$ de nióbio e $80,39 \%$ de alumínio, o que comprova que o fato da cor ser clara não é necessariamente nióbio puro.

Nos pontos 3 e 4 que possuem uma cor intermediária e escura, possuem uma alta concentração de alumínio, mas podemos observar também concentrações de nióbio.

A amostra de Nióbio recebida pela CBMM, foi caracterizada por Vilas Boas [8] e ficou constatado que possui $93,3 \%$ de nióbio puro, com isso podemos indicar uma 
possível homogeneização do nióbio e da liga Al-Mg 5052F por forjamento em todas as regiões analisadas da solda e a introdução do nióbio como elemento de liga, tendo em vista que as concentrações de nióbio nos pontos 1, 2 e 3 são semelhantes a concentração de magnésio que é o elemento de liga principal do alumínio 5052F soldado.

No que se refere a homogeneização do nióbio e da liga Al-Mg 5052F por forjamento, pode-se dizer que é causada pelo movimento de translação e rotação da ferramenta na soldagem por FSW, que produz uma combinação de conformação por extrusão ao redor do pino e forjamento nas regiões adjacentes ao ombro, isso define dois lados na região soldada: lado de avanço e lado de retrocesso, conforme estudo de Carvalho [10].

No momento em que a liga de Al-Mg está sendo soldada, os efeitos de extrusão e forjamento consolidam a solda, finalizando o processo de conformação plástica. $O$ FSW pode ser considerado como um processo de conformação a quente, por envolver um aquecimento e fluxo de massa.

O lado de avanço da peça a ser soldada é o lado que coincide com o sentido da velocidade de rotação da ferramenta, o lado de recuo tem o sentido das velocidades de translação e rotação opostos. As características mecânicas nessas regiões podem ser distintas, principalmente na soldagem de materiais diferentes.

Os lados de avanço e recuo são regiões com diferenças na formação da microestrutura do metal. O lado de avanço, é caracterizado microestruturalmente por uma fronteira entre a região do núcleo e a zona termo-mecanicamente afetada (ZTMA). O núcleo apresenta grãos pequenos enquanto que a região da ZTMA apresenta grãos grandes e alongados. No lado de retrocesso a solda possui uma microestrutura mais complexa, não apresenta limite bem definido entre a região do núcleo e a ZTMA. Na região do núcleo existe a presença de grãos menores que os da ZTMA, entretanto, é possível perceber também a presença de grãos maiores que dificulta a distinção entre as regiões como comentado por Carvalho [10].

Alguns mecanismos envolvendo temperatura e velocidade podem ser determinantes para o acabamento do material. $O$ material ao ser forjado a quente precisa ser aquecido a uma temperatura que possa lhe permitir elevada plasticidade, desde o início até o final do processo de fabricação. A diferença entre as temperaturas inicial e final do forjamento é conhecida como intervalo de temperatura de forjamento. Torna-se interessante aquecer o metal a altas temperaturas, pois sua forjabilidade aumenta com o aumento desta. O perigo do superaquecimento, no entanto, é um fator limitante para esse aumento. A temperatura varia para cada tipo de material que é submetido ao forjamento, para aços o aquecimento é em torno de 1100 a $1280^{\circ} \mathrm{C}$, ou seja, a um nível de 180 a $200^{\circ} \mathrm{C}$ abaixo da temperatura de fusão, dependendo de sua composição, obtendo-se assim uma estrutura de grãos grossos. Durante o forjamento esses grãos são refinados, mas, se a temperatura final do forjamento for alta (acima de $900^{\circ} \mathrm{C}$ ) os grãos poderão crescer durante o esfriamento da peça ao ar e a mesma, nesse caso, poderá ter resistência mecânica menor. Em relação a liga de Al-Mg a faixa de temperatura de conformação a quente varia 320 a $560^{\circ} \mathrm{C}$ que para soldagem por FSW pode ser considerado como uma vantagem, por não necessitar de uma ferramenta que suporte elevadas temperaturas para consolidar a solda, de acordo com Paiva [9].

O alumínio e suas ligas são considerados com uma densidade relativamente baixa de $2,7 \mathrm{~g} / \mathrm{cm}^{3}$, em comparação com uma densidade de $7,9 \mathrm{~g} / \mathrm{cm}^{3}$ para o aço. 0 alumínio metálico obtido pelo processo de redução tem $99,7 \%$ de pureza e passa 
por adição de elementos como ferro, silício, manganês entre outros na composição, conforme Callister [11].

Um outro fator muito importante na conformação a quente de materiais forjados é a velocidade de deformação, que tem influência sobre a resistência que o metal opõe sobre a conformação. A resistência a conformação é maior para os processos dinâmicos quando comparados aos estáticos. No processo de soldagem por FSW a pressão é gerada por atrito, através do contado direto com o pino em movimento e a peça, essa pressão causa diretamente aumento da temperatura, sendo esse, um mecanismo de forjamento na liga a ser soldada.

\section{CONCLUSÃO}

No processo de soldagem por FSW, foi verificado que a adição de nióbio na junta não interferiu na operacionalidade do processo e a solda foi realizada sem problemas, sem defeitos superficiais e com aparência de boa mistura entre o nióbio e o liga de Al-Mg 5052F. Ao analisar a macroestrutura e microestrutura da solda com adição de nióbio observou-se uma boa homogeneidade da solda, sem a presença de descontinuidades e nugget mais refinados sendo um indicativo de aumento de dureza do material. Diferente da macroestrutura e microestrutura do alumínio onde apresentou descontinuidades nas extremidades inferior do metal soldado.

$\mathrm{Na}$ microscopia eletrônica de varredura foi observado regiões claras, intermediárias e escuras, mas não sendo uma separação do Al-Mg 5052F do nióbio pois existe uma concentração de ambos em cada ponto verificado, com isso podemos indicar uma possível homogeneização do nióbio e da liga Al-Mg 5052F por forjamento, formando possivelmente um composto intermetálico.

Com esses dados podemos concluir que a introdução do nióbio nas juntas soldadas de alumínio pelo processo FSW teve resultados além das expectativas, com uma boa mistura, podendo ser melhorada a aplicabilidade nas soldagens com alumínio nas indústrias por esse processo ou até mesmo na produção de novas ligas, levando em consideração os parâmetros de forjamento para a soldagem.

\section{Agradecimentos}

Os autores agradecem a todos que contribuíram para a realização deste trabalho, em particular, a Companhia Brasileira de Metalurgia e Mineração (CBMM), pelo fornecimento da amostra de Nióbio Metálico, ao grupo LCAM da Universidade Federal do Pará, que viabilizou com seus equipamentos a análise do material e ao Prof. M.e. Paulo D'angelo Costa Assunção que acompanhou e orientou todo o desenvolvimento desse artigo.

\section{REFERÊNCIAS}

1 THOMAS, W. M. Friction stir butt welding. International Patent no. 9125978.8. Dez. 1991. [Acesso em 16 mai. 2017]; disponível em: http://www.patent.gov.uk.

2 ABAL. Centro de Informações Automotivo e de Transportes. ALUAUTO. n.10; 2006. [Acesso em 15 mai. 2017]; disponível em: http://www.abal.org.br.

3 Cruz, Fernando Moura, Carlos. Friction stir welding, Potencial de aplicação da indústria aeroespacial; 2009. 
4 Capelari, Tiago V., Avaliação da geometria da ferramenta e parâmetros do processo FSW na soldagem da liga de alumínio [Tese Mestrado]. Porto Alegre: Universidade Federal do Rio Grande do Sul; 2006.

5 Inada, K. Effect of gap on FSW joint formation and development of friction powder processing. Science and Technology of Welding and Joining. 2010; 131-136.

6 Mariano C., Avaliação da compressibilidade de misturas de pós de nióbio e alumínio ativada mecanicamente [Tese Mestrado]. São Paulo: Instituto de Pesquisas Energéticas e Nucleares. 2008; p. 27.

7 Mishra, R. S; MA, Z. Y. Friction Stir Welding and Processing. A review jornal. Materials Science e Engineering, Volume (50). 2005; 1 - 78.

8 Vilas Boas G. P., Ferreira V. O., Cardoso I. T. A. P., Assunção P. D. C. Caracterização de Nióbio Metálico através de microscopia eletrônica de varredura (MEV), In: Congresso Nacional de Engenharia Mecânica. 2016; Fortaleza; Brasil. p. 1-6.

9 Paiva, C, Marcelo. Forjamento. [Acesso em 15 de jun, 2017]; disponível em: https://burocracismo.wordpress.com.

10 Carvalho, Jaqueline, Mára. Análise estática e de fadiga de uniões soldadas por Friction stir Welding; 2012.

11 Callister, William D. Jr., Ciência e engenharia de materiais: uma introdução. $8^{a}$ edição. Rio de Janeiro: LTC; 2012. 